\title{
Geolocalización y realidad aumentada para un aprendizaje ubicuo en la formación inicial del profesorado
}

\author{
Geolocation and Augmented Reality for Ubiquitous Learning in Initial Teacher Education
}

Lourdes Villalustre Martínez

Universidad de Oviedo

villalustrelourdes@uniovi.es

M. Esther del Moral Pérez

Universidad de Oviedo

emoral@uniovi.es

Fecha presentación: 13/06/2018 | Aceptación: 18/09/2018 |Publicación: 21/12/2018

\begin{abstract}
Resumen
En el marco de la asignatura de Tecnologías de la Información y Comunicación del Grado de Maestro en Educación Infantil de la Universidad de Oviedo (España) los 121 futuros maestros que la cursaron, diseñaron itinerarios formativos aumentados mediante geolocalización, dirigidos a escolares de educación infantil para favorecer el desarrollo de competencias básicas. Así, tras su realización se llevó a cabo una evaluación mediante 12 indicadores agrupados en tres dimensiones de análisis: aprendizaje ubicuo potenciado, realidad expandida diseñada y nivel de innovación. Los resultados obtenidos revelan que la dimensión relativa a la realidad expandida diseñada fue desarrollada en mayor medida, mientras que los discentes tuvieron mayores dificultades para promover la innovación en sus propuestas. Con todo, los estudiantes universitarios han demostrado haber adquirido un nivel medio-alto tanto en la destreza y manejo de los recursos tecnológicos propios de la realidad aumentada, como en la potencialidad didáctica de los itinerarios interactivos.
\end{abstract}

Palabras clave: realidad aumentada; geolocalización; itinerarios formativos; aprendizaje ubicuo

\section{Resum}

En el marc de l'assignatura de Tecnologies de la Informació i Comunicació del Grau de Mestre en Educació Infantil de la Universitat d'Oviedo (Espanya) els 121 futurs mestres que la van cursar van dissenyar itineraris formatius augmentats mitjançant geolocalització, dirigits a escolars d'educació infantil, per afavorir el desenvolupament de competències bàsiques. Així, després de la seva realització es va dur a terme una avaluació mitjançant 12 indicadors agrupats en tres dimensions d'anàlisi: aprenentatge ubic potenciat, realitat expandida dissenyada i nivell d'innovació. Els resultats obtinguts revelen que la dimensió relativa a la realitat expandida dissenyada va ser desenvolupada en major mesura, mentre que els estudiants van tenir més dificultats per promoure la innovació en les seves propostes. $\mathrm{Amb}$ tot, los estudiants univesitaris han demostrat haver adquirit un nivell mitjà-alt tant en la destresa i maneig dels recursos tecnològics propis de la realitat augmentada, com en la potencialitat didàctica dels itineraris interactius.

Paraules clau: realitat augmentada; geolocalització; itineraris formatius: aprenentatge ubic

\begin{abstract}
In the subject of Information and Communication Technologies of the Master's Degree in Early Childhood Education at the University of Oviedo (Spain), the 121 future teachers who studied it designed training itineraries augmented by geolocation, aimed at children in early childhood education, to favor the development of basic skills. Thus, after its realization an evaluation was carried out by means of 12 indicators grouped in three analysis dimensions: enhanced ubiquitous learning, expanded reality designed and level of innovation. The results obtained reveal that the dimension related to the expanded reality designed was developed to a greater extent, while the students had greater difficulties to promote innovation in their proposals. However, the university students has shown to have acquired a medium-high
\end{abstract}


Villalustre Martínez, L., y del Moral Pérez, M. E. (2018). Geolocalización y realidad aumentada para un aprendizaje ubicuo en la formación inicial del profesorado. @tic revista d'innovació educativa, 21, 40-48.

level both in the skill and handling of the technological resources of the augmented reality, and in the didactic potential of the interactive itineraries.

Key Words: augmented reality; geolocation; training itineraries; ubiquitous learning

\section{Introducción}

Las tecnologías móviles están redefiniendo los espacios de aprendizaje, más allá de las aulas convencionales, sustituyendo los modelos físicos por otros digitales. Los dispositivos multitáctiles posibilitan el acceso y manipulación de recursos tridimensionales, a través de la realidad aumentada, incrementando la experiencia sensorial. De este modo, las prácticas formativas pueden llevarse a cabo en cualquier momento y lugar gracias a la flexibilidad que les confieren las tecnologías móviles. Estas se caracterizan por su capacidad de personalización, su portabilidad e interacción así como por su ubicuidad para acceder e interactuar con recursos de diversa naturaleza desde diferentes contextos. Por ello, en el ámbito educativo se están adoptando las tecnologías multitáctiles para optimizar los procesos formativos, debido a su gran potencial, dando lugar al denominado aprendizaje móvil o ubicuo (Abernathy, 2001).

El aprendizaje ubicuo ofrece numerosas oportunidades para la enseñanza. Cattaneo, Motta, y Gurtner (2015) destacan los beneficios de su utilización en las aulas desde el punto de vista de la usabilidad, la efectividad y la satisfacción de los estudiantes. Sharples (2000) considera que potencia el pensamiento espacial para la representación y manipulación de información así como la resolución de problemas. Por su parte, Melhuish y Falloon (2010) inciden en su flexibilidad para acceder a los recursos formativos sin limitaciones de tiempo y espacio. Mientras que Mtebe y Raisamo (2014) ponen el acento en el papel activo que adoptan los estudiantes con la utilización de estos nuevos dispositivos móviles en las aulas. Por otro lado, el aprendizaje ubicuo permite configurar un universo enriquecido de conocimientos gracias a la aparición de nuevas tecnologías como la realidad aumentada y la geolocalización, ampliando sus posibilidades, así como el desarrollo de nuevas experiencias.

La realidad aumentada (en adelante RA) y la geolocalización son tecnologías disruptivas que propician un nuevo modelo de aprendizaje. Con ellas se obtiene una mayor información de los elementos del entorno, al combinar los contenidos físicos con los digitales (Billinghurst y Duenser, 2012; Lee, 2012), convirtiendo al mundo real en interactivo y digital. La superposición de información añadida a través de sistemas móviles mediante la geolocalización nos permite visualizar imágenes, vídeos, etc. sobre el lugar en el que nos encontremos al activarse el sensor GPS en el punto exacto previamente marcado (Leiva y Moreno, 2015). Estas tecnologías móviles proporcionan formas alternativas para acceder al conocimiento desde cualquier campo, potenciando la colaboración (Kaufmann y Schmalstieg, 2003) y despertando la motivación e implicación del alumnado (Di Serio, Ibáñez y Kloos, 2013) al aportar un cierto grado de innovación y de sorpresa entre los estudiantes.

Teniendo en cuenta estas premisas, en la asignatura de Tecnologías de la Información y Comunicación del Grado de Maestro en Educación Infantil, los futuros maestros diseñaron itinerarios interactivos con geolocalización y realidad aumentada para potenciar el desarrollo de competencias y promover el aprendizaje ubicuo entre los niños/as de educación infantil. Tras su desarrollo se llevó a cabo un análisis de las experiencias inmersivas creadas por los estudiantes universitarios en función de tres dimensiones: 1) El aprendizaje ubicuo potenciado; 2) La realidad expandida diseñada y 3) La innovación puesta en juego, cuyos resultados se presentarán a lo largo del presente trabajo. No sin antes delimitar conceptualmente los principales elementos sobre los que pivota la experiencia desarrollada.

\section{Aprendizaje ubicuo con realidad aumentada: una nueva ecología de la educación}

Por aprendizaje ubicuo puede entenderse, aquel que no se circunscribe a un contexto determinado ni viene condicionado por un espacio concreto, sino que la adquisición de nuevos conocimientos puede producirse en cualquier situación en la que se encuentre el sujeto, independientemente del momento y lugar (Burbules, 2012). Y, sin ser un concepto novedoso, pues el aprendizaje es un proceso natural e intrínseco al ser humano, este se ve potenciado de forma exponencial gracias a las posibilidades que las tecnologías móviles le ofrecen (Zapata, 2012), mostrándole todo tipo de información a partir de la interacción con los objetos que le circundan, ya sean físicos o virtuales. Provocando un fenómeno de intercambio de información, donde simultáneamente los aprendices pueden contribuir al conocimiento de otros, al compartir sus experiencias y saberes personales, dejándolos indelebles en los objetos y lugares (físicos o virtuales) accesibles a cualquiera (Cope y Kalantzis, 2009), los cuales pueden ser recuperados, por ejemplo, a partir de QR.

Este nuevo concepto del aprendizaje ubicuo, ligado a la potencialidad de las nuevas herramientas digitales, está conformando una nueva ecología de la enseñanza, -tal como señalan Cobo y Moravec (2011), quienes lo califican de "invisible"-, que incide en la necesidad de que la educación debe ayudar a que los sujetos extraigan significado de sus propias experiencias de interacción con otros, en el contexto tecnológico donde se desenvuelven, para convertirlo en conocimiento. Así pues, en este escenario, la ubicuidad referida al proceso de aprendizaje se halla estrechamente relacionada con la proliferación del uso de los dispositivos móviles y las redes sociales, así como con la adopción de las narrativas digitales que estos implican (Caldeiro y Schwartzman, 2013).

Por otro lado, este tipo de aprendizaje -apegado al aquí y ahora- adquiere una nueva dimensión con la realidad aumentada, al proporcionar al aprendiz una visión enriquecida de los elementos físicos reales que le rodean, permitiéndole ver la información complementaria -o los objetos virtuales añadidos- que otros han dejado vinculados, por ejemplo, a edificios, monumentos artísticos, etc., haciendo que su visión trascienda a las cualidades meramente físicas de los mencionados elementos. $E$ incluso, le ofrezca experiencias que superen sus limitaciones (Del Moral y Villalustre, 2013), aumentando su percepción y, por ende, dotándole de nuevas oportunidades para transformar esa información en conocimiento, al tiempo 
que le permite incorporar la suya propia.

A este respecto, investigaciones como la de De la Torre, Martin-Dorta, Saorín, Carbonell, y Carrera (2015) subrayan las ventajas derivadas de utilizar aplicaciones de RA -mediante tabletas- para desarrollar el pensamiento espacial, necesario para la representación y manipulación de objetos tridimensionales-, estableciendo unas pautas didácticas que garantizaran los aprendizajes tras romper con las barreras físicas del aula. Por su parte, la experiencia de Gallego, Rubia, Arribas, y Muñoz (2015) pone de manifiesto cómo un diseño educativo colaborativo en un marco de aprendizaje ubicuo con $\mathrm{QR}$ ha generado un proceso formativo muy enriquecedor, a partir de la interacción con objetos mediante móviles en distintos momentos y espacios (aula, medio natural, etc). Innovaciones que conjugan la RA favoreciendo el aprendizaje ubicuo están en pleno desarrollo; la experiencia que se describe en estas páginas se apoya en la geolocalización como estrategia formativa ligada al medio.

\section{Geolocalización e itinerarios didácticos interactivos}

Los itinerarios o excursiones son una estrategia didáctica ampliamente utilizada en el área de didáctica de las ciencias sociales y experimentales, que permite acercarse y estimular el conocimiento del patrimonio natural y cultural (García de la Vega, 2012; López y Segura, 2013). Si bien, con la proliferación de los dispositivos móviles y los avances tecnológicos estas propuestas se han visto enriquecidas con la utilización de la geolocalización y la realidad aumentada para dotarlas de mayor interactividad y ofrecer nuevas oportunidades para promover el aprendizaje dentro y fuera del aula. La geolocalización permite asociar contenidos digitales (imágenes, vídeos, audios, etc.) a unas coordenadas GPS previamente establecidas y activables mediante un dispositivo móvil.

La movilidad que confieren los nuevos dispositivos digitales posibilita el desarrollo de novedosas estrategias didácticas para potenciar la adquisición de nuevos conocimientos (Villa, Tapia, y López, 2010). Con la geolocalización es posible planificar actividades formativas fuera del aula para promover experiencias educativas en contextos próximos a la realidad y al medio, contribuyendo a que el aprendizaje sea realmente significativo y situado (Paul, 2014; Zapata, 2015). En la planificación de actividades formativas con geolocalización se debe enfatizar tanto el contexto en el que estas se desarrollen, como los mecanismos de interacción que se proyecten con el entorno, los cuales se encuentran mediados por los dispositivos móviles. En consecuencia, para Martin y Ertzberger (2013) las prácticas educativas basadas en la utilización de tecnologías móviles y geolocalización deben ser auténticas, significativas y participativas.

Hernando, Arévalo, Catasús, y Mon (2014) ponen de relieve la gran accesibilidad a este tipo de tecnologías en el ámbito educativo, lo que favorece su utilización con una finalidad didáctica y formativa. Para ello, se pueden emplear diferentes estrategias centradas no solo en el diseño de itinerarios sino también en la formulación de procesos de indagación o proyectos situados, tal y como establece Sharples (2003). Así, la geolocalización posibilita la apertura y la interrelación del centro educativo con el entorno, ofreciendo numerosas oportunidades para generar espacios de aprendizaje más ricos y motivadores. Con ella, se potencia el interés y curiosidad de los discentes, ofreciendo la posibilidad de visitar lugares y conocer el entorno bajo una óptica diferente a través de los elementos generados de manera virtual (Dunleavy y Dede, 2014; Kesim y Ozarslan, 2012).

La propuesta de actividades basada en la utilización de la geolocalización facilita la asimilación de los procesos de aprendizaje, incrementa la motivación y posibilita el pensamiento divergente mediante la búsqueda de respuestas creativas y originales a los problemas prácticos que se pueden presentar sobre el terreno, al tiempo que aporta una mayor interactividad significativa (Bacca, Baldiris, Fabregat, y Graf, 2015). Por todo ello, desde la asignatura de Tecnologías de la Información y Comunicación del Grado de Maestro en Educación Infantil se ha visto la pertinencia de su integración en la misma dadas las múltiples posibilidades didácticas y formativas que genera para la formación de los futuros maestros, al posibilitar el desarrollo de metodologías más activas, flexibles y dinámicas.

4. Itinerarios interactivos con geolocalización y realidad aumentada desarrollados por futuros maestros de educación infantil

En el marco de la asignatura Tecnologías de la Información y Comunicación (TIC) del Grado de Maestro en Educación Infantil de la Universidad de Oviedo, se llevaron a cabo diversas prácticas formativas basadas en la creación de recursos didácticos con realidad aumentada (Villalustre, 2018). Entre ellas, los futuros maestros debían diseñar itinerarios interactivos destinados a niños/as de educación infantil mediante el uso de la geolocalización y la realidad aumentada para el desarrollo de las competencias lingüística, matemática y competencias básicas en ciencia y tecnología.

Con ello, se pretendía que los futuros maestros aprendieran a crear recursos de realidad aumentada con una intencionalidad educativa mediante el uso de diferentes herramientas web, detalladas más adelante en el punto 3.3.3, así como a descubrir su potencial didáctico para favorecer la adquisición de nuevos conocimientos de manera colaborativa en tres áreas: 1) matemáticas, a través del reconocimiento de las formas geométricas de edificios representativos y estatuas visitadas en los itinerarios, etc.; 2) lengua, mediante el desarrollo de vocabulario básico en castellano, inglés y asturiano a partir de las rutas propuestas; y 3) científicos, a través del conocimiento del entorno.

\subsection{Objetivo}

El presente estudio analiza los 35 itinerarios interactivos diseñados por los 121 estudiantes universitarios del Grado de Maestro en Educación Infantil, basados en la utilización de la geolocalización y la realidad aumentada, a través de diversas herramientas detalladas en el punto 3.3.3 del presente trabajo. Con el diseño de los itinerarios se pretendía favorecer la adquisición de nuevos conocimientos en las áreas de matemáticas, lengua y ciencia, con el fin de determinar su capacidad para potenciar un aprendizaje ubicuo, promoviendo el uso de recursos aumentados, así como la originalidad de las propuestas.

\subsection{Fases para su ejecución}

Los estudiantes debían desarrollar un proyecto centrado en el diseño de un itinerario interactivo con geolocalización y/o realidad aumentada para favorecer el desarrollo de las competencias lingüística, matemática y competencias básicas en ciencia y tecnología. Para 
Villalustre Martínez, L., y del Moral Pérez, M. E. (2018). Geolocalización y realidad aumentada para un aprendizaje ubicuo en la formación inicial del profesorado. @tic revista d'innovació educativa, 21, 40-48.

ello, se establecieron las siguientes fases de ejecución:

Fase I. Selección de competencias e identificación del entorno

Se propone a los futuros maestros en educación infantil la creación de itinerarios interactivos con geolocalización y/o realidad aumentada para abordar las competencias con mayor presencia, en cuanto al número de horas semanales, en los currículos escolares: competencia lingüística, competencia matemática y competencias básicas en ciencia y tecnología. Los discentes debían seleccionar libremente la competencia y el contenido asociado a esta, a abordar en los itinerarios, pudiendo centrarlos en una única competencia de las tres propuestas o en varias. De igual modo, se deja a elección de los estudiantes la zona geográfica sobre la que desarrollarán su itinerario dentro de la geografía asturiana.

\section{Fase II. Creación del itinerario}

Una vez delimitada la zona geográfica y los contenidos a abordar, los futuros maestros diseñaron los itinerarios interactivos, en concreto se crearon 35 itinerarios, en los que se añadió a la información física presente en las localizaciones seleccionadas por los discentes los contenidos digitales a través de imágenes, vídeos y audios para ampliar la experiencia.

Fase III. Elaboración de la guía didáctica

Una vez creados los itinerarios interactivos, los futuros maestros de infantil debían elaborar una guía didáctica que acompañará al escenario inmersivo. En ella se debía incluir:

- Los objetivos didácticos que guiaron el diseño del itinerario.

- Los contenidos que se abordan en él.

- Las competencias que se desarrollan.

- Actividades formativas para potenciar la colaboración.

- Aspectos organizativos: temporalización, organización y gestión de los niños/as de infantil fuera del aula, utilización de los dispositivos móviles, etc.

Fase IV: Evaluación de los itinerarios desarrollados por los futuros maestros

Tras el diseño de los itinerarios interactivos por parte de los estudiantes universitarios, se procedió a efectuar una evaluación de los mismos, partir de una rúbrica de evaluación creada al efecto, en función de tres dimensiones: 1) El aprendizaje ubicuo potenciado; 2) La realidad expandida diseñada y 3) La innovación puesta en juego.

\subsection{Presentación de los itinerarios creados por los futuros maestros \\ Los 121 estudiantes -organizados en equipos de 3 ó 4 personas-, que cursaron la asignatura de Tecnologías de la Información y Comunicación del Grado de Maestro en Educación Infantil de la Universidad de Oviedo crearon 35 itinerarios interactivos sobre diferentes zonas de la geografía asturiana (España) desarrollados con geolocalización y/o realidad aumentada. En concreto las zonas seleccionadas por ellos para diseñar los itinerarios fueron: el $21 \%$ de las rutas propuestas por los estudiantes se centraron en desarrollar un circuito por el centro de la cuidad de Oviedo; al igual que aquellos que}

propusieron una ruta por el Parque San Francisco de Oviedo (21\%); el 17\% de los itinerarios tuvieron lugar por las principales localizaciones de Gijón; y el 11\% de las propuestas se ubicaron en el Parque Natural de Cabarceno. Mientras que el $9 \%$ de las mismas se centraron en el Jardín Botánico y en el Parque de Isabel La Católica (Gijón), y el 6\% de los itinerarios se centraron en la Ruta del Camín Encantau de Llanes. Por último, el $3 \%$ de las propuestas se situaron en la Granja Escuela Conlleu y en diseñar rutas por los principales lugares de Cangas de Narcea.

\subsubsection{Competencias y contenidos abordados}

Los itinerarios diseñados por los estudiantes podían centrarse exclusivamente en una de las tres competencias propuestas (lingüística, matemática o científica) o en acometer varias. De este modo, como se presenta en la tabla 1, los estudiantes abordaron las siguientes competencias y contenidos en los 35 itinerarios creados:

\begin{tabular}{llc}
\hline \multicolumn{1}{c}{ Competencia } & \multicolumn{1}{c}{ Contenidos } & Frecuencia (\%) \\
\hline Lingoistica & $\begin{array}{l}\text { Desarrollando vocabulario básico en castellano, inglés y } \\
\text { asturiano. Contenidos Iiterarios (autores y obras de } \\
\text { referencia a partir de estatuas visitadas). }\end{array}$ & $16(30 \%)$ \\
\hline Matemática & $\begin{array}{l}\text { Reconocimiento de las tormas geométricas de edificios } \\
\text { representativos y estatuas visitadas en los itinerarios. }\end{array}$ & $9(17 \%)$ \\
\hline Ciencia y tecnologia & $\begin{array}{l}\text { Conocimiento del entorno inmediato. Identificación de } \\
\text { animales y plantas. Astronomia. }\end{array}$ & $29(53 \%)$ \\
\hline
\end{tabular}

Tabla 1. Identificación de las competencias y contenidos abordados en los itinerarios interactivos. Elaboración propia.

Así, podemos observar como el 30\% de los itinerarios diseñados por los futuros maestros abordaron contenidos lingüísticos, encaminados a potenciar el desarrollo de vocabulario básico que sería trabajado a lo largo de ruta y la adquisición de nociones literarias gracias a la visita de diferentes estatuas de autores de referencia para introducir en las aulas sus principales obras. De igual modo, el $17 \%$ de los itinerarios propuestos incluían el desarrollo de conocimientos matemáticos, sobre todo, referidos al reconocimiento de formas geométricas presentes en el entorno. Por último, el $53 \%$ de las rutas trabajaban contenidos científicos, encaminados a potenciar el reconocimiento del medio, así como la identificación de plantas y animales presentes en los diferentes recorridos.

\subsubsection{Estrategias utilizadas e itinerarios creados}

Una vez seleccionados por los estudiantes universitarios, los contenidos y la zona geográfica a abordar, diseñaron los itinerarios interactivos mediante el uso de la geolocalización y/o realidad aumentada. Para ello, se propone a los futuros maestros diferentes estrategias para diseñar los itinerarios. En la tabla 2 se presentan las adoptadas por los estudiantes: 
Villalustre Martínez, L., y del Moral Pérez, M. E. (2018). Geolocalización y realidad aumentada para un aprendizaje ubicuo en la formación inicial del profesorado. @tic revista d'innovació educativa, 21, 40-48.

\begin{tabular}{|c|c|c|}
\hline Tipo de Estrategia & Breve descripción & Frecuencia (\%) \\
\hline $\begin{array}{l}\text { 1) Juego de pistas a través } \\
\text { de geolocalización }\end{array}$ & $\begin{array}{l}\text { Información a través de imágenes, videos, audios, ... } \\
\text { para ofrecer pistas sobre el terrene que permitan } \\
\text { continuar con el recorrido en función de la ubicación }\end{array}$ & $10(29 \%)$ \\
\hline $\begin{array}{l}\text { 2) Juego de preguntas con } \\
\text { geolocalización }\end{array}$ & $\begin{array}{l}\text { Propuesta de preguntas con varias opciones de } \\
\text { respuesta con informacion visual que se activan en } \\
\text { funcion de las coordenadas GPS en determinados } \\
\text { lugares del recoorido }\end{array}$ & $12(35 \%)$ \\
\hline $\begin{array}{l}\text { 3) Máquina del tiempo a } \\
\text { traves de geolocalización }\end{array}$ & $\begin{array}{l}\text { Superposicion de información visual en determinados } \\
\text { lugares para apreciar el paso del tiempo en función de } \\
\text { las coordenadas GPS }\end{array}$ & $3(8 \%)$ \\
\hline 4) Gymkana con Aurasma & $\begin{array}{l}\text { Aoceso a información a partir de imágenes del entorno } \\
\text { (ej. carteles, vallas pubilictarias, etc.) para obtener pistas } \\
\text { que permitan concluir el recorrico. }\end{array}$ & 4 (11\%) \\
\hline $\begin{array}{l}\text { 5) Búsqueda del tesoro } \\
\text { con códigos QR }\end{array}$ & $\begin{array}{l}\text { Se presenta un itinerario con codigos QR presentes en } \\
\text { determinados lugares que deben ser escaneados para } \\
\text { acceder a las pistas que permitan encontrar el tesoro. }\end{array}$ & $5(14 \%)$ \\
\hline $\begin{array}{l}\text { 6) Observacion del } \\
\text { firmamento }\end{array}$ & $\begin{array}{l}\text { Actividad nocturna para, a través de las geolocalizacion, } \\
\text { visualizar y obtener información sobre las estrellas, los, } \\
\text { planetas, las constelaciones, etc. }\end{array}$ & $1(3 \%)$ \\
\hline
\end{tabular}

Tabla 2. Distribución de los itinerarios interactivos diseñados por los futuros maestros de educación infantil en función de la estrategia lúdica/didáctica adoptada. Elaboración propia.

La mayoría de los discentes optaron por diseñar itinerarios interactivos basados en juegos de pistas, donde gracias a la geolocalización se potencia el conocimiento de manera motivadora. En ellos, se añade información de diversa índole. Por ejemplo, en uno de los itinerarios diseñados para llevarse a cabo en el Jardín Botánico de Gijón (España), se creó un escenario (figura 1) tomando como base la localización del jardín, para repartir por él una serie de pista, en forma de adivinanzas, relacionadas con el mundo vegetal, que los niños/as de educación infantil tendrán que ir resolviendo para avanzar en el itinerario. En cada coordenada GPS señalada en el mapa, se incorpora una adivinanza y una pista a modo de imagen, video, enlace web, para facilitar su resolución, y ofrecer información para encaminarse al siguiente punto GPS donde se activará nuevamente otra pista (o adivinanza, en este caso).

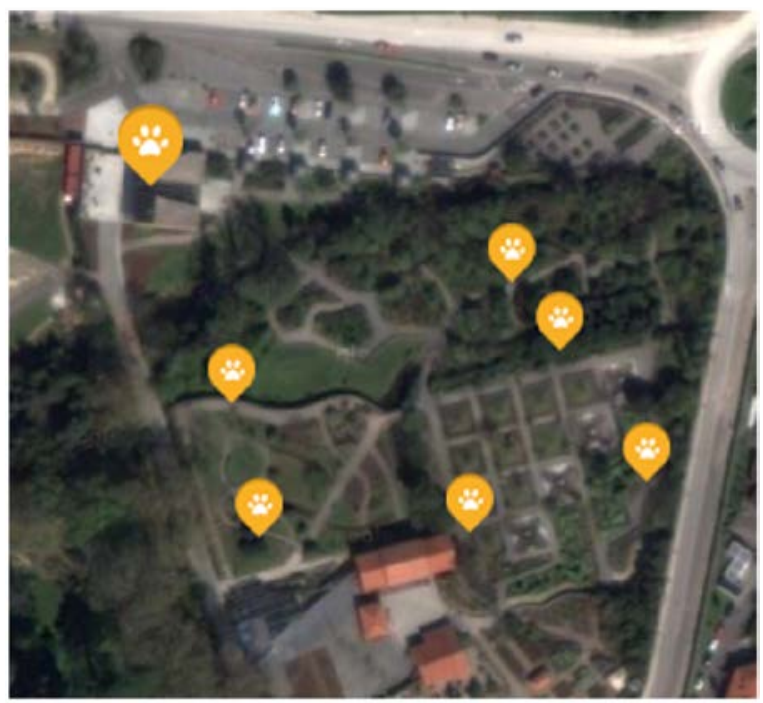

Figura 1. Escenario con geolocalización basado en un juego de pistas a desarrollar en el Jardín Botánico de Gijón (España). Fuente: Escenario creado por estudiantes de la asignatura de TIC aplicadas a la Educación con la herramienta Eduloc (http://eduloc.net).

De forma similar se produce con los juegos de preguntas, donde se incorporan en lugar de pistas, preguntas con opciones de respuesta acompañadas de diferentes elementos multimedia. Por el contrario, las propuestas basadas en la máquina del tiempo pretenden contrastar el entorno actual con otro situado en el pasado o en el futuro. En la figura 2 se muestra un itinerario creado por los estudiantes universitarios sobre el centro y casco histórico, donde se efectúa una comparación entre la ciudad de Oviedo (España) de ahora y el de antes, a través de imágenes de archivo, con las que se puede apreciar el paso del tiempo, y la transformación que ha sufrido el entorno que nos rodea.

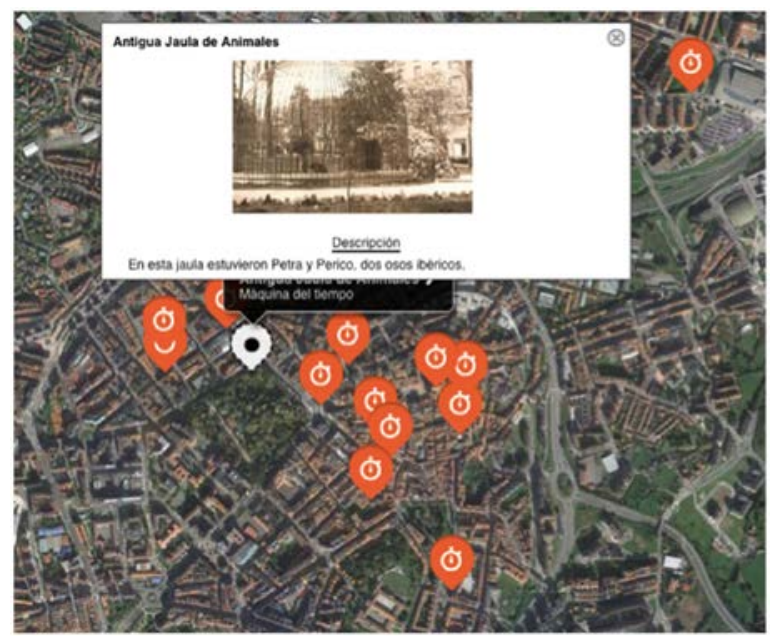

Figura 2. Escenario con geolocalización basado en la Máquina del Tiempo a desarrollar por el centro de Oviedo (España). Fuente: Escenario creado por estudiantes de la asignatura de TIC aplicadas a la Educación con la herramienta Eduloc (http://eduloc.net).

Otras propuestas iban encaminadas a elaborar una Gymkana o una Búsqueda del Tesoro a partir de códigos QR o imágenes como activadoras. Ejemplo de ello, es el itinerario elaborado para desarrollar en el Parque de Isabel La Católica (Gijón, España), donde previamente los futuros maestros elaboran los códigos QR con las pistas, a modo de imágenes y videos, que llevarán al tesoro escondido. De modo que los niños/as de educación infantil deben seguir el itinerario marcado para recabar todas las pistas ocultas en los códigos QR, que les permitirá, al mismo tiempo, ir conociendo de una manera entretenida, los animales y plantas que habitan en dicho parque.

\subsubsection{Herramientas utilizadas}

Para elaborar estos itinerarios los estudiantes universitarios emplearon, por un lado, Eduloc (http://www.eduloc.net) para generar escenarios interactivos activados a partir de coordenadas GPS. Y por otro, las herramientas web Aurasma (https://www.aurasma.com) y diversos generadores de códigos QR (http://www.codigos-qr.com).

Para la observación del firmamento las aplicaciones seleccionadas por los discentes fueron Sky Map (https://play.google.com/store/apps/details?id=com.goo gle.android.stardroid\&hl=es) y Mapa Estelar (https://play.google.com/store/apps/details?id=com.esc apistgames.starchart\&hl=es). 
Villalustre Martínez, L., y del Moral Pérez, M. E. (2018). Geolocalización y realidad aumentada para un aprendizaje ubicuo en la formación inicial del profesorado. @tic revista d'innovació educativa, 21, 40-48.

\section{Evaluación de los aprendizajes a partir de la iniciativa llevada a cabo \\ 5.1. Contexto y muestra}

Una vez concluida la experiencia, se lleva a cabo una evaluación de los 35 itinerarios interactivos con geolocalización y/o realidad aumentada creados por los 121 futuros maestros de educación infantil, en el marco de la asignatura de Tecnologías de la Información y Comunicación del Grado de Maestro en Educación Infantil de la Universidad de Oviedo (España).

\subsection{Instrumento}

La evaluación de los aprendizajes adquiridos por los estudiantes se lleva a cabo a través de una rúbrica diseñada al efecto, y constituida por 12 indicadores agrupados en tres dimensiones de análisis como se aprecia en la tabla 3:

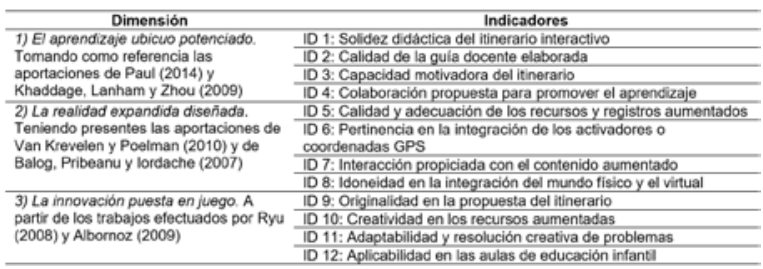

Tabla 3. Dimensiones e indicadores de evaluación. Elaboración propia.

Delimitadas las dimensiones de análisis y los indicadores de evaluación se elabora una rúbrica analítica con tres niveles de valoración (alto, medio y bajo) para obtener una visión de conjunto de los itinerarios interactivos elaborados por los futuros maestros (ver tabla 4). Su objetivo era doble: por un lado, evaluar la práctica innovadora llevada a cabo por parte de los estudiantes universitarios; y por otro, detallar -a modo de rúbrica- los criterios específicos que guiaron la valoración de la misma.

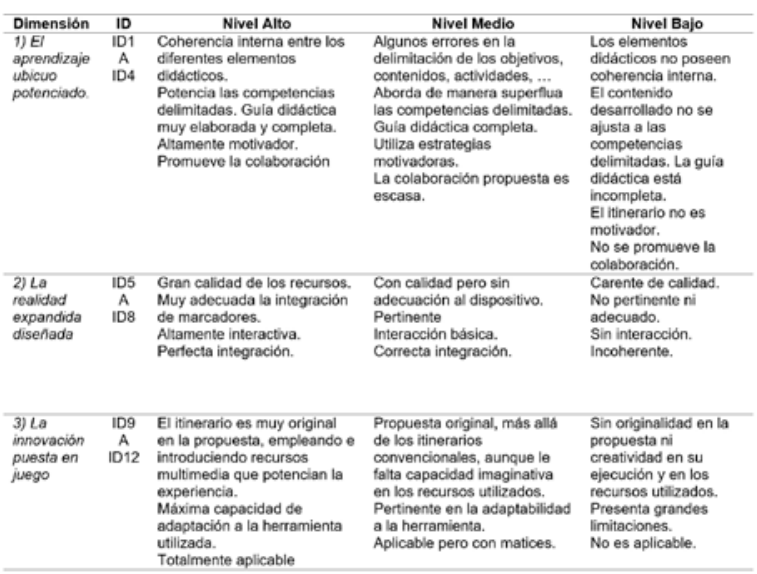

Tabla 4. Rubrica para evaluar los itinerarios interactivos creados por los futuros maestros. Elaboración propia.

Con la rúbrica presentada en la tabla 4 , se desarrolló el proceso de evaluación de los itinerarios interactivos diseñados por los estudiantes universitarios basados en la utilización de geolocalización y/o realidad aumentada, obteniendo los resultados que se presentan en el siguiente apartado.

\subsection{Resultados obtenidos}

A continuación, se muestran los resultados obtenidos de la evaluación llevada a cabo de los 35 itinerarios interactivos creados por 121 estudiantes, organizados en equipos de 3 ó 4 personas.

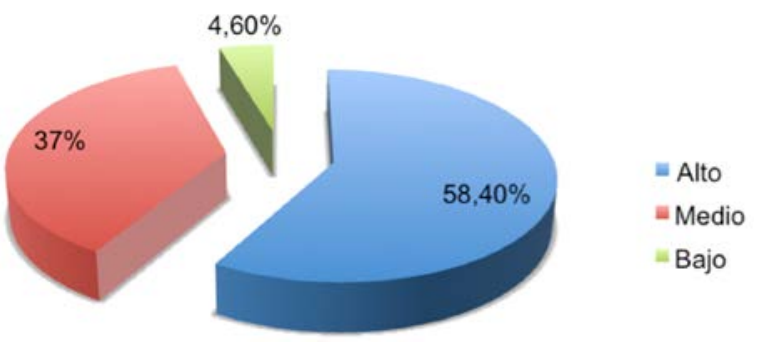

Gráfico 1. Distribución porcentual de la evaluación global efectuada de los itinerarios interactivos. Elaboración propia.

En el gráfico 1, se aprecia cómo más de la mitad $(58,40 \%)$ de los estudiantes obtuvieron un alto nivel de ejecución, atendiendo a los criterios previamente delimitados para cada una de las tres dimensiones enunciadas, mientras que $37 \%$ de los mismos fueron valorados con un nivel medio y un $4,6 \%$ con un nivel bajo.

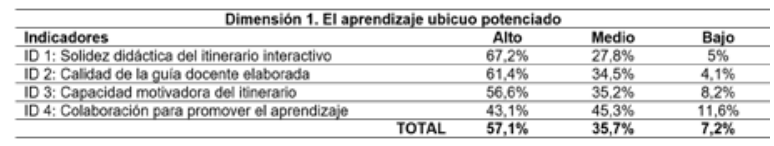

Tabla 5. Distribución porcentual de los diferentes niveles desarrollados en los itinerarios en relación al aprendizaje ubicuo potenciado. Elaboración propia.

Un análisis más detallado en función de cada dimensión y sus correspondientes indicadores de evaluación (tabla 5), revela que más del $67 \%$ de los itinerarios creados por los estudiantes poseían un alto nivel de solidez didáctica, existiendo una coherencia interna entre los objetivos fijados, las competencias delimitadas, las actividades propuestas, etc. De igual modo, algo más del $60 \%$ de las guías docentes creadas por los futuros maestros tenían una calidad alta, incorporando y detallando todos los elementos requeridos para la elaboración de las propuestas formativas diseñadas con geolocalización y/o realidad aumentada. Si bien más de la mitad de las rutas interactivas elaboradas por los discentes universitarios eran altamente motivadoras, el $45,3 \%$ de ellas apenas promovían la colaboración a través de la planificación de actividades que la posibilitasen.

\begin{tabular}{|c|c|c|c|}
\hline \multicolumn{4}{|c|}{ Dimensión 2. La realidad expandida diseñ. } \\
\hline Indicadores & Alto & Medio & Bajo \\
\hline $\begin{array}{l}\text { ID 5: Calidad y adecuación de los recursos y registros } \\
\text { aumentados }\end{array}$ & $57,1 \%$ & $39,5 \%$ & $3,4 \%$ \\
\hline $\begin{array}{l}\text { ID 6: Pertinencia en la integración de los activadores o } \\
\text { coordenadas GPS }\end{array}$ & $70,2 \%$ & $27,5 \%$ & $2,3 \%$ \\
\hline ID 7: Interacción propiciada con el contenido aumentado & & $23.2 \%$ & $3.5 \%$ \\
\hline ID 8: Idoneidad en la integración del mundo fisico y el & $69.4 \%$ & $26.5 \%$ & $\frac{4,1 \%}{3.3 \%}$ \\
\hline
\end{tabular}

Tabla 6. Distribución porcentual de los diferentes niveles desarrollados en los itinerarios en relación a la realidad expandida diseñada por los estudiantes. Elaboración propia.

Por otro lado, un alto porcentaje de los itinerarios analizados facilitaban la interacción con el contenido 
aumentado (73,3\%), al igual que el $70,2 \%$ que mostraban un alto nivel de pertinencia en la integración de los activadores o coordenadas GPS, tal y como aparece reflejado en la tabla 6 . De igual modo, el $69,4 \%$ de los itinerarios presentaba una correcta integración entre el mundo físico y el virtual, lo que contribuía a ofrecer una experiencia formativa más inmersiva y enriquecedora. Cabe destacar que algo más del $57 \%$ de los recursos y registros aumentados gozaban de una alta calidad y eran apropiados, mientras que el 39,5\% de los mismos poseían una calidad media, pues aunque los contenidos abordados en los recursos eran pertinentes, estos no eran adecuados para ser visionados en dispositivos móviles, -sobre todo vídeos- debido al exceso de peso y/o duración.

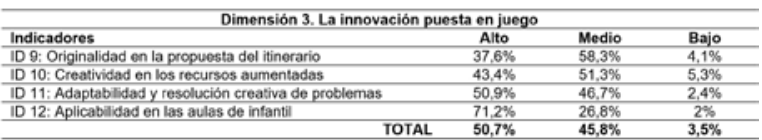

Tabla 7. Distribución porcentual de los diferentes niveles desarrollados en los itinerarios en relación a la innovación puesta en juego. Elaboración propia.

Por último, en relación a la innovación puesta en juego en los diferentes itinerarios, cabe destacar que más de la mitad de los mismos (58,3\% y 51,3\%) obtuvieron un nivel medio, pues aún ofreciendo propuestas originales, estos estaban carentes de capacidad imaginativa en la elaboración y selección de los recursos utilizados (tabla 7 ), mientras que el $50,9 \%$ reflejaban un alto nivel alto en la plasmación de soluciones imaginativas y creativas para hacer frente a las limitaciones técnicas de la herramienta utilizada. De igual modo, el $71,2 \%$ de los itinerarios poseían un alto nivel de aplicabilidad a las aulas de educación infantil, adaptando su recorrido y contenido a las peculiaridades cognitivas y evolutivas de esta etapa educativa.

\section{Discusión y conclusiones}

Los itinerarios interactivos se están convirtiendo en una eficaz estrategia didáctica que combina las oportunidades que presenta la realidad aumentada y el aprendizaje ubicuo para facilitar la construcción del conocimiento en los diferentes niveles educativos. En concreto, la experiencia desarrollada en las aulas universitarias de formación del profesorado ha resultado una práctica innovadora muy motivadora, que ha implicado activamente a las/os futuras/os maestros/as para diseñar itinerarios formativos aumentados, utilizando la geolocalización en tanto recursos didácticos y con el apoyo de herramientas móviles, dirigidos a escolares de educación infantil, para favorecer el desarrollo de las competencias básicas, en consonancia con lo apuntado por Balog, Pribeanu, e lordache (2007). Así, alrededor de la mitad de los itinerarios diseñados de forma grupal (53\%) abordan contenidos científicos, ligados a potenciar el reconocimiento del medio; especialmente, a identificar plantas y animales autóctonos del ecosistema elegido para sus recorridos. El 30\% de los mismos se centra en aspectos de carácter lingüístico, encaminados a ampliar el vocabulario básico relacionado con la ruta elegida y a conocer autores literarios y sus obras a partir de las estatuas que se encuentran por la ciudad. Y otro $17 \%$ de los mismos trabaja aspectos matemáticos, referidos al reconocimiento de formas geométricas presentes en el entorno. La mayoría de ellos han optado por la estrategia didáctica del juego de pistas, gymkana, viaje en la máquina del tiempo, etc., de gran atractivo y con un gran componente lúdico considerando que iban dirigidos al alumnado de educación infantil. Fueron elaborados con diversas herramientas como: Eduloc, Aurasma y generadores de códigos QR, y otras más específicas, como Sky Map y Mapa Estelar, lo que ha activado su competencia digital.

Tras evaluar los itinerarios diseñados con una rúbrica ad hoc de carácter cualitativo, que contempla tres dimensiones de análisis: aprendizaje ubicuo potenciado, realidad expandida diseñada y nivel de innovación plasmada, a partir de diversos indicadores, se ha podido constatar que algo más de la mitad $(57,1 \%)$ ha alcanzado un nivel alto en la dimensión aprendizaje ubicuo, referido a la consistencia didáctica tanto de su diseño como de la guía para su explotación, la implicación colaborativa que promueve y su potencial motivador, mientras aproximadamente el 36\% de ellos ha alcanzado un nivel medio, y sólo el $7 \%$ un nivel bajo. Por otro lado, respecto a la dimensión realidad expandida diseñada, vinculada tanto a calidad y adecuación que presentan los recursos y registros utilizados, como al grado de pertinencia de la integración de los activadores creados o coordenadas GPS utilizadas, junto a la interacción propiciada y la idoneidad mostrada respecto a la integración del mundo físico y el virtual, se constata que el $67,5 \%$ alcanzaron un nivel alto, aproximadamente el $30 \%$ un nivel medio, y un 3\% un nivel bajo.

Y con relación a la dimensión de innovación puesta en juego, evaluada a partir de su grado de originalidad, creatividad, adaptabilidad y nivel de aplicabilidad en las aulas de educación infantil, se ha observado que la mitad $(50,7 \%)$ alcanzan un nivel alto, mientras otro $45,8 \%$ un nivel medio y el marginal $3 \%$, que se repite, presenta un nivel bajo.

Sin duda, la práctica formativa descrita ha supuesto una experiencia innovadora de primer orden para los/as maestros/as de infantil en formación, pues para algunos/as se trataba de un primer contacto con estas tecnologías emergentes, sin embargo, la mayoría ha demostrado haber adquirido un nivel medio-alto tanto en la destreza y manejo de los recursos tecnológicos propios de la realidad aumentada y geolocalización, como en la potencialidad didáctica de los itinerarios interactivos diseñados, abordando mediante estrategias lúdico-didácticas las competencias básicas de educación infantil. En esta misma línea, los trabajos desarrollados por Moreno Martínez y Leiva Olivencia (2017), y Wu, Lee, Chang y Liang (2013) refuerzan la necesidad de introducir estas tecnologías en la formación de los futuros maestros para potenciar su integración didáctica en las aulas más allá de uso instrumental de una manera inclusiva y dinámica.

\section{Bibliografía}

Abernathy, D. J. (2001). Get ready for m-learning. Training \& Development, 55(2), 10-20.

Albornoz, M. (2009). Indicadores de innovación: las dificultades de un concepto en evolución. Revista Iberoamericana de Ciencia Tecnología y Sociedad, 5(13), 9-25. Recuperado de: http://ir.uv.es/p3XTVQo 
Villalustre Martínez, L., y del Moral Pérez, M. E. (2018). Geolocalización y realidad aumentada para un aprendizaje ubicuo en la formación inicial del profesorado. @tic revista d'innovació educativa, 21, 40-48.

Bacca, J., Baldiris, S., Fabregat, R., y Graf, S. (2015). Mobile Augmented Reality in Vocational Education and Training. Procedia Computer Science, 75, 4958. https://doi.org/10.1016/j.procs.2015.12.203

Balog, A., Pribeanu, C., y lordache, D. (2007). Augmented reality in schools: Preliminary evaluation results from a summer school. International Journal of Social Sciences, 2(3), 163$166 . \quad$ Recuperado de: http://citeseerx.ist.psu.edu/viewdoc/summary?doi= 10.1.1.193.4893

Billinghurst, M., Duenser, A. (2012). Augmented reality in the classroom. Computer, 7, 56-63. https://doi.org/10.1109/MC.2012.111

Burbules, N.C. (2012). Ubiquitous Learning and the Future of Teaching. Encounters, 13, 3-14. https://doi.org/10.24908/eoe-ese-rse.v13i0.4472

Cattaneo, A. A., Motta, E., y Gurtner, J. L. (2015). Evaluating a Mobile and Online System for Apprentices' Learning Documentation in Vocational Education: Usability, Effectiveness and Satisfaction. International Journal of Mobile and Blended Learning (IJMBL), 7(3), 40-58. https://doi.org/10.4018/IJMBL.2015070103

Caldeiro, G., Schwartzman, G. (2013). Aprendizaje ubicuo. Entre lo disperso, lo efímero y lo importante: nuevas perspectivas para la educación en línea. En D. Brocca y M.M. Clapés (ed.), I Jornadas Nacionales y III Jornadas de Experiencias e Investigación en Educación a Distancia y Tecnología Educativa (PROED). Córdoba, Argentina: Universidad Nacional de Córdoba. Recuperado de: http://ir.uv.es/DFG80oM

Cobo, C., Moravec, J.W. (2011). Aprendizaje Invisible. Hacia una nueva ecología de la educación. Barcelona: Laboratori de Mitjans Interactius / Publicacions i Edicions de la Universitat de Barcelona.

Cope, B., Kalantzis, M. (2009). Ubiquitous Learning. Exploring the anywhere/anytime possibilities for learning in the age of digital media. Champaign, IL: University of Illinois Press.

De la Torre, J., Martin-Dorta, N., Saorín, J.L., Carbonell, C., y Carrera, M. (2015). Entorno de aprendizaje ubicuo con realidad aumentada y tabletas para estimular la comprensión del espacio tridimensional. Revista de Educación a Distancia, 37, 1-10. Recuperado de: https://revistas.um.es/red/article/view/234041

Del Moral, M.E., Villalustre, L. (2013). Realidad aumentada: experimentando en el aula en 3D. En R. Ron, A. Álvarez y P. Núñez (Coords.). Smarthphones y tablets: ¿enseñan o distraen? Madrid: ESIC.

Di Serio, Á., Ibáñez, M. B., y Kloos, C. D. (2013). Impact of an augmented reality system on students' motivation for a visual art course. Computers \& Education, 68, 586-596. https://doi.org/10.1016/j.compedu.2012.03.002

Dunleavy, M., Dede, C. (2014). Augmented reality teaching and learning. Handbook of research on educational communications and technology. New York: Springer.

Gallego, V.,Rubia, B., Arribas, H.F., y Muñoz, J.A. (2015). Aprendizaje ubicuo: Un proceso formativo en Educación Física en el Medio Natural. Actas de la XXIII Jornadas Universitarias de Tecnología Educativa, JUTE 2015, Badajoz, España, Junio 2015. https://doi.org/10.17398/1695-288X.15.1.59

García de la Vega, A. (2012). El aprendizaje basado en problemas en los itinerarios didácticos vinculados al patrimonio. Educación y Futuro, 27, 155-175. Recuperado de: https://cesdonbosco.com/documentos/revistaeyf/E YF_27.pdf

Hernando, M. M., Arévalo, C. G., Catasús, M. G., y Mon, C. Z. (2014). Mobile learning: a collaborative experience using QR codes. Revista de Universidad y Sociedad del Conocimiento, 11(1), 175-191. http://dx.doi.org/10.7238/rusc.v11i1.1899

Kaufmann, H., Schmalstieg, D. (2003). Mathematics and geometry education with collaborative augmented reality. Computers \& Graphics, 27(3), 339-345. 8493(03)00028-1

Khaddage, F., Lanham, E., Zhou, W. (2009). A Mobile Learning Model for Universities. International Journal of Interactive Mobile Technologies, 3(1), 18-23. https://doi.org/10.3991/ijim.v3s1.949

Kesim, M., Ozarslan, Y. (2012). Augmented reality in education: current technologies and the potential for education. Procedia-Social and Behavioral Sciences, 47, 297-302. https://doi.org/10.1016/j.sbspro.2012.06.654

Lee, K. (2012). Augmented reality in education and training. TechTrends, 56 (2), 13-21. Recuperado de: http://ir.uv.es/UeOm3jK

Leiva Olivencia, J. J., Moreno Martínez, N. M. (2015). Tecnologías de geolocalización y realidad aumentada en contextos educativos. Didáctica, Innovación y Multimedia, 31, 1-18. Recuperado de: http://www.pangea.org/dim/revista.htm

López de Haro, F., Segura Serrano, J. A. (2013). Los itinerarios didácticos: un recurso interdisciplinar y vertebrador del curriculum. Espiral. Cuadernos del Profesorado, 6(12), 15-31. http://dx.doi.org/10.25115/ecp.v6i12.954

Martin, F., Ertzberger, J. (2013). Here and now mobile learning: An experimental study on the use of mobile technology. Computers \& Education, 68, 76-85.

https://doi.org/10.1016/j.compedu.2013.04.021

Mtebe, J. S., Raisamo, R. (2014). Investigating students' behavioural intention to adopt and use mobile learning in higher education in East Africa. International. Journal of Education and Development using Information and Communication Technology, 10(3), 4-20. Recuperado de: http://ijedict.dec.uwi.edu/viewissue.php?id=39 
Villalustre Martínez, L., y del Moral Pérez, M. E. (2018). Geolocalización y realidad aumentada para un aprendizaje ubicuo en la formación inicial del profesorado. @tic revista d'innovació educativa, 21, 40-48.

Melhuish, K., Falloon, G. (2010). Looking to the future: M-learning with the iPad. Computers in New Zealand Schools: Learning, Leading, Technology, 22(3), 1-16. Recuperado de: https://www.otago.ac.nz/cdelt/otago064509.pdf

Moreno Martínez, N.M., Leiva Olivencia, J.J. (2017). Experiencias formativas de uso didáctico de la realidad aumentada con alumnado del grado de educación primaria en la universidad de Málaga. Revista Edmetic, 6 (1), 81-104. https://doi.org/10.21071/edmetic.v6i1.5809

Paul, T. V. (2014). An Evaluation of the Effectiveness of E-Learning, Mobile Learning, and Instructor-Led Training in Organizational Training and Development. The Journal of Human Resource and Adult Learning, 10(2), 1-13. Recuperado de: http://www.hraljournal.com/Page/1\%20Tyechia\%2 OPaul-new.pdf

Ryu, H. (2008). Innovative Mobile Learning: Techniques and Technologies: Techniques and Technologies. London: IGI Global.

Sharples, M. (2000). The Design of Personal Mobile Technologies for Lifelong Learning. Computers \& Education, 34, 177-193. https://doi.org/10.1016/S0360-1315(99)00044-5

Sharples, M. (2003). Disruptive devices: mobile technology for conversational learning. International Journal of Continuing Engineering Education and Lifelong Learning, 12(5), 504--520. https://doi.org/10.1504/IJCEELL.2002.002148

Van Krevelen, D. W. F., Poelman, R. (2010). A survey of augmented reality technologies, applications and limitations. International Journal of Virtual Reality, 9(2), 1-20. Recuperado de: http://ir.uv.es/YXTwO9b

Villa, H., Tapia, F., y López, C. (2010). Aprendizaje ubicuo en la enseñanza de las matemáticas. Revista Estudios Culturales, 5, 123-136. Recuperado de: https://dialnet.unirioja.es/descarga/articulo/373998 3.pdf
Villalustre, L. (2018). Rincones aumentados: una innovación en la formación inicial de maestros de educación infantil. En X. Carrera et al. (Ed.). Educación con tecnologia un compromiso social. Aproximaciones desde la investigción y la innovaciónn. (pp. 888-893). Lleida: Universidad de Lleida.

Wu, H. K., Lee, S. W. Y., Chang, H. Y., y Liang, J. C. (2013). Current status, opportunities and challenges of augmented reality in education. Computers \& Education, 62, 41-49. https://doi.org/10.1016/j.compedu.2012.10.024

Zapata, M. (2012). Calidad en entornos ubicuos de aprendizaje. Revista de Educación a Distancia, 31, 1-10.

Zapata, M. (2015). Teorías y modelos sobre el aprendizaje en entornos conectados y ubicuos. Bases para un nuevo modelo teórico a partir de una visión crítica del "conectivismo". Teoría de la Educación: Educación y Cultura en la Sociedad de la Información, 16(1), 69-102. http://dx.doi.org/10.14201/eks201516169102

| Cita recomendada de este artículo

Villalustre Martínez, L., y del Moral Pérez, M. E. (2018). Geolocalización y realidad aumentada para un aprendizaje ubicuo en la formación inicial del profesorado. @tic revista d'innovació educativa, 21, 40-48.

https://doi.org/10.7203/attic.21.12633 